\title{
Pengembangan Simulasi Kejadian Diskret Berbasis Paket Simmer pada $\mathbf{R}$
}

\author{
I G.A. Anom Yudistira" \\ Statistics Department, School of Computer Science, \\ Bina Nusantara University, \\ Jakarta, Indonesia 11480 \\ i.yudistira@binus.ac.id \\ *Correspondence: i.yudistira@binus.ac.id
}

\begin{abstract}
This study aims to describe the various capabilities of the simmer package on $R$, especially in running a discrete event simulation model, then develop a DES simulation model building technique, which is effective and can represent real systems well, and explore the simulation output on this simmer, both in statistical summary form and parameter estimation. The method used in this research is the literature study, with descriptive and exploratory approaches. Model development is more effective when it is carried out starting from simple models, to more complex forms step by step, and describing the system using a flow chart. Replication for simulations is easy to perform, so as to get standard error values for model parameter estimators. The stages in developing a discrete event simulation model with a simmer, start with compiling a simple flowchart to a more complex form, and replication is carried out. The simmer output in the form of data.frame makes it very easy to further process the output. The simple $R$ API on simmer will also make it easier to simulate.
\end{abstract}

Keywords: Simulation; DES; simmer; R programming.

Abstrak - Penelitian ini bertujuan untuk men-deskripsikan berbagai kemampuan package simmer pada $R$ khususnya dalam menjalankan model simulasi kejadian diskret, mengembang-kan suatu teknikpembangunan modelsimulasi $D E S$, yang efektif dan bisa merepresentasikan sistem nyata secara baik, dan mengeksplorasi keluaran simulasi pada simmer ini, baik dalam bentuk ringkasan statistik dan pendugaan parameternya. Metode yang digunakan dalam penelitian ini adalah metode kepustakaan, dengan pendekatan deskriptif dan eksploratif. Pengembangan model lebih efektif bila dila-kukan mulai dari model yang sederhana, hingga bentuk-bentuk yang lebih kompleks secara langkah demi langkah, dan mendeskrip-sikan sistem menggunakan diagram alir. Replikasi untuk simulasi mudah dilakukan, sehingga mendapatkan nilai galat baku untuk penduga parameter model. Tahap-tahap dalam mengembangkan model simulasi ke-jadian diskret dengan simmer, dimulai dengan menyusun bagan alir sederhana sampai dalam bentuk yang lebih kompleks, serta dilakukan replikasi. Keluaran simmer dalam bentuk data.frame, sangat memudahkan dalam mengolah keluaran tersebut lebih lanjut. $R$ API pada simmer yang sederhana juga akan memudahkan dalam melakukan simulasi.

Kata kunci: Simulasi; DES; simmer; Pemograman R.

\section{PENDAHULUAN}

Model simulasi digunakan untuk mempelajari suatu sistem, khususnya apabila sulit / mahal atau berbahaya jika mempelajari sistem secara langsung (Banks, 2014). Disamping itu sistem nyata yang kompleks, hampir tidak mungkin dipelajari dengan model analitik, untuk itu simulasi merupakan pilihan terakhir yang tidak bisa di tawar lagi. Selanjutnya Shannon (1975), memberikan definisi terhadap simulasi yaitu suatu proses untuk mendesain model sistem nyata dan melakukan eksperimen terhadap model tersebut, untuk tujuan memahami perilaku sistem atau mengevaluasi berbagai strategi atau seperangkat kriteria.

R merupakan suatu bahasa pemrograman fungsional, yang berbasis sumber terbuka (open source), sehingga bisa diakses secara gratis. Bahasa $\mathrm{R}$ ini sangat dikenal dikalangan ilmuwan dan statistikawan, bahkan merambah penggunaannya diberbagai bidang terapan. Dikalangan akademisi, $\mathrm{R}$ banyak digunakan untuk membantu dalam aspek komputasi untuk memecahkan masalah penelitian. Dalam hal kajian simulasi, R memiliki kekuatan pada simulasi monte-carlo (static stochastic simulation techniques). Kelemahan utama R sebelum tahun 2017, 
adalah tidak tersedianya suatu package untuk memecahkan masalah simulasi kejadian diskret (discrete event simulation, DES) yang handal. Sehingga pemrograman DES dengan menggunakan R menjadi sangat sulit. Sejak tahun 2017 dikembangkan package simmer (Ucar dan Smeets, 2017), yang merupakan package DES untuk R yang memungkinkan pemodelan berorientasi proses tingkat tinggi, sejalan dengan simulator modern lainnya. Ucar, Smeets dan Azcorra (2017), menyebutkan bahwa, paket simmer memudahkan untuk membangun model simulasi kejadian-diskrit pada R. Paket dirancang sebagai kerangka kerja berorientasi proses yang generik namun handal, yang ditulis dalam $\mathrm{C}++$, sehingga eksekusinya relatif cepat dan robust. Paket simmer juga dilengkapi dengan kemampuan monitoring yang otomatis, dengan keluaran defaultnya dalam bentuk tabel. Paket ini juga menyediakan API untuk R yang kaya dan fleksibel, yang berpusat di sekitar konsep lintasan, yaitu jalur umum dalam model simulasi untuk lintasan entiti. Fungsi trajectory () digunakan untuk membangkitkan objek dengan kelas trajectory. Hanya saja belum dikembangkan teknik untuk membangun model DES berbasis simmer, sehingga efektif untuk merepresentasi-kan sistem yang kompleks.

\subsection{Tujuan}

Penelitian ini bertujuan untuk (1) mendeskripsikan berbagai kemampuan package simmer pada $\mathrm{R}$ untuk menjalankan model simulasi kejadian diskret (DES), (2) mengembangkan suatu teknik pembangunan model simulasi DES, yang efektif dan bisa merepresentasikan sistem nyata secara baik. Serta (3) mengeksplorasi keluaran simulasi dengan menggunakan package simmer ini, baik dalam bentuk ringkasan statistik dan pendugaan parameternya. $\mathrm{R}$ yang memiliki kekuatan pada analisis statistik dan grafik, akan sangat menarik apabila dikombinasikan dengan kemampuan package simmer. Sinergi package simmer dan package - package lain pada $\mathrm{R}$ tentu akan menarik untuk dianalisis dan dibahas dalam penelitian ini.

Pesaing utama simmer adalah SimPy (Tim SimPy, 2017) dan SimJulia (Lauwens, 2017), yang masing-masing dikembangkan untuk Bahasa Python dan Julia.

\section{METODOLOGI PENELITIAN}

Metode yang digunakan dalam penelitian ini adalah metode kepustakaan, dengan pendekatan deskriptif dan eksploratif.

Langkah-langkah dalam penelitian ini adalah:

1) Telaah pustaka untuk mendapatkan pemahaman yang lengkap terhadap R API (antarmuka pemrograman aplikasi). R API untuk simmer adalah berbentuk fungsi-fungsi R.

2) Telaah pustaka untuk mendapatkan pemahaman yang lengkap terhadap struktur lingkungan dari kelas simmer.

3) Membangun baganatauflowchartyangmenggambarkan sistem

4) Membangun script $R$ yang dalam bentuk yang paling sederhana

5) Meningkatkan kompleksitas sistem satu tingkat
6) Apakah cukup mewakili sitem, jika belum kembali kelangkah 5)

7) Selesai

\subsection{Batasan}

Proses pemodelan dan simulasi disajikan pada yaitu dimulai dari perumusan masalah, sampai pada pengambilan keputusan. Penelitian ini di-batasi hanya pada aspek pembangunan model, khususnya pada pengembangan model simu-lasi. Aspek pengumpulan data, pengujian asumsi-asumsi model dan pelaksanaan percobaan terhadap model diluar ruang lingkup penelitian ini.

\section{HASIL DAN PEMBAHASAN}

Sistem Kejadian Diskret yang paling sederhana adalah sistem antrian dengan server tunggal (antrian tunggal). Deskripsi sistemnya adalah sebagai berikut: Suatu sistem mempunyai server tunggal yang melayani entiti untuk suatu transaksi. Bagannya adalah sebagai berikut,

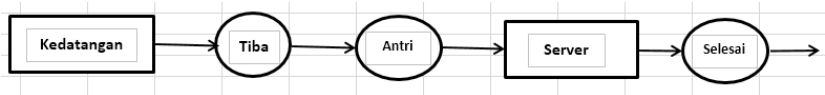

Gambar 1. Sistem sederhana (server tunggal)

Segiempat menunjukkan suatu aktivitas sedangkan bentuk bulat/oval menunjukkan status sistem. Setiap aktivitas yang diawali oleh status antri, yang artinya aktivitas tersebut membutuhkan sumberdaya. Entiti datang dengan suatu proses kedatangan tertentu (waktu konstan atau acak), kemudian waktu kedatang-annya (tiba) dicatat sebagai start time. Entiti menuju server untuk melakukan proses transaksi, tetapi apabila server tidak tersedia (sedang melayani entiti lain), maka entiti masuk dalam antrian. Entiti mendapat layanan server selama waktu tertentu, dicatat sebagai activity time (konstan atau acak). Setelah entiti selesai mendapatkan proses layanan, maka akan keluar dari sistem kembali ke lingkungan, dicatat sebagai end time. Waktu start time, end time dan activity time akan dicatat (dimonitor) oleh simmer secara otomatis. Catatan waktu ini dapat diperoleh dengan menggunakan fungsi get_mon_arrival, yang disajikan dalam objek data. frame (tabel). Sistem ini mem-punyai dua jenis input simulasi yaitu waktu kedatangan / antar kedatangan, dan waktu aktivitas server (lamanya server melayani). Misalnya kedatangan entiti menyebar eksponesial dengan laju entiti per unit waktu dan lama layanan menyebar eksponensial dengan laju entiti per unit waktu (angka 0.4 dan 0.45 hanyalah sebagai gambaran agar bisa dieksekusi oleh R). Lintasan entiti adalah tiba mengambil sumber daya (seize) proses pelayanan yang mebutuhkan waktu (timeout) melepas sumber daya (release) keluar dari sistem. Script $\mathrm{R}$ untuk lintasan ini adalah sebagai berikut:

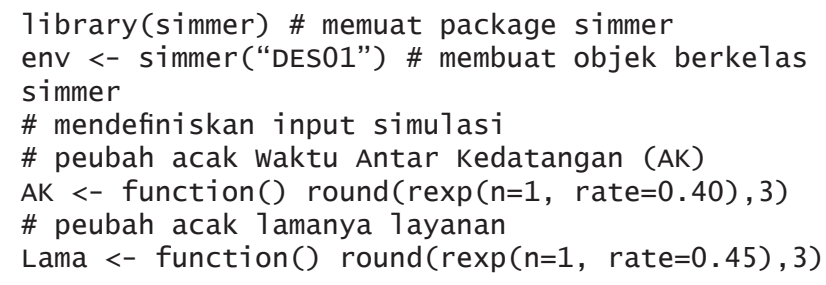




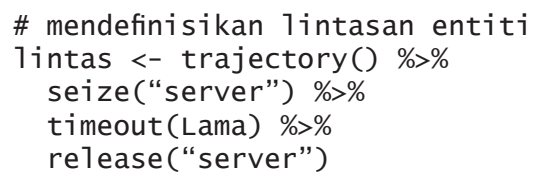

Script R untuk simulasi, selalu didahului dengan pendefinisian lingkungan simmer (env <simmer ("DES01")). Nama lingkungan-nya adalah "DES01" dan disimpan pada objek env.

Kemudian dilanjutkan dengan pendefinisan input simulasi. Koding untuk lintasan terdiri dari 3 fungsi utama, yaitu penciptaan kelas trajectory, seize, timeout dan release. Apabila aktivitas tidak membutuhkan sumberdaya, maka fungsi seize, dan release dihilangkan. Input simulasi untuk lamanya aktivitas server melayani suatu entiti ("Lama"), dijadikan sebagai nilai argumen untuk fungsi timeout. Setelah mendefinisikan lintasan entiti, pada lingkungan simulasi env ditambah-kan sumberdaya (resource) dengan nama "Server", sejumlah yang tersedia (dalam hal ini 1). Fungsi R (pada paket simmer) untuk melakukan ini adalah add_resource. Kemudian linkungan env, ditambahkan fungsi untuk membangkitkan entiti, beserta waktu kedatangan / antar kedatangan, yaitu menggunakan fungsi add_generator. Script secara lengkap adalah sebagai berikut:

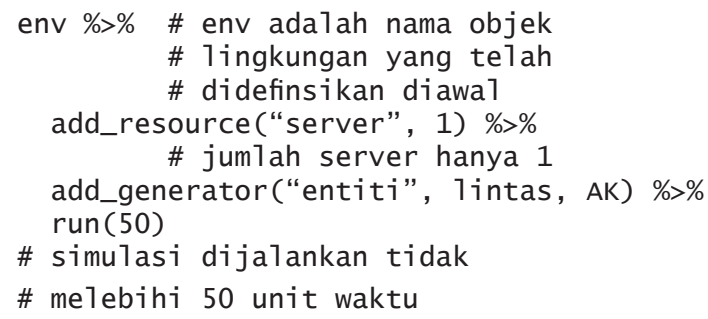

Hasil monitoring simulasi dapat diambil dengan fungsi get_mon_, yang hasilnya berupa data.frame (tabel).

output.arr <- get_mon_arrivals(env)

output.resc <- get_mon_resources(env)

Fungsi get_mon_attributes(), akan menghasilkan nilai-nilai attribute dari simulasi. Pada kasus sekarang ini belum menggunakan fungsi attribute.

Fungsi run(50) menunjukkan bahwa simulasi dijalankan sampai 50 unit waktu. Jadi secara garis besar script $\mathrm{R}$ untuk simulasi kejadian diskret (DES), dengan menggunakan simmer terdiri dari empat komponen dasar, yaitu

1) Inisialisasi

a) Pendefinisan lingkungan simulasi $\rightarrow$ env $<-$ simmer()

b) Pendefinisan input simulasi $\rightarrow$ AK $<-$ function(); Lama <- function()

c) Pendefinisian lintasan $\rightarrow 1$ intas $<-$ trajectory ()

\# objek 1intas berkelas

\# trajectory

2) Penambahan resources dan pembangkitan kedatangan entiti pada lingkungan simulasi:
a) add_resources()
b) add_generator()

3) Menampilkan hasil simulasi, yang berupa tabel

a) get_mon_arrivals()

b) get_mon_resources()

c) get_mon_attributes()
Hasil monitoring kedatangan (arrivals) dan sumberdaya (resources), dapat dilihat pada lampiran.

\subsection{Peningkatan Kompleksitas Sistem}

- Penambahan jumlah server paralel identik dan antrian tunggal

Sekarang server ditambah menjadi dua unit server yang identik. Entiti yang datang akan mengantri pada satu jalur antrian, dan segera akan mendapatkan layanan, jika minimal salah satu dari dari kedua server dalam keadaan free (idle) sehingga siap dipakai. Diagram sistem antrian dengan dua server paralel dan satu jalur antrian adalah sebagai berikut:

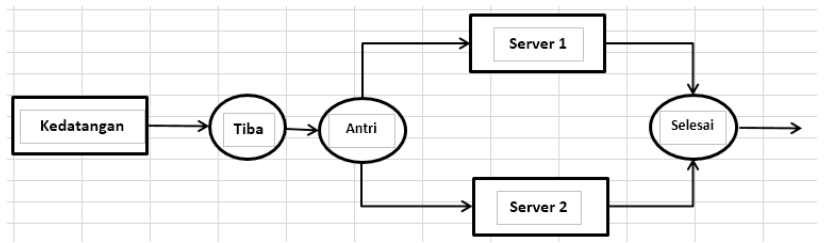

Gambar 2. Sistem Paralel Identik

Jumlah server yang paralel dapat diperluas menjadi $n$ $>2$ server. Perubahan hanya dilaku-kan pada penambahan jumlah (kapasitas) resources, yaitu menjadi dua, sedangkan kom-ponen lain tidak berubah.

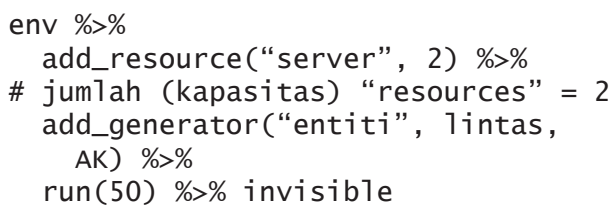

- Penambahan server serial dan aktivitas tanpa resources

Apabila sistem dikembangkan dengan deskripsi sebagai berikut: Setelah entiti mendapatkan la-yanan disalah satu server 1 atau server 2, ke-mudian berlanjut secara serial ke server 3, setelah dari server 3 entiti melakukan aktivitas tanpa reources. Bagannya digambarkan seba-gai berikut:

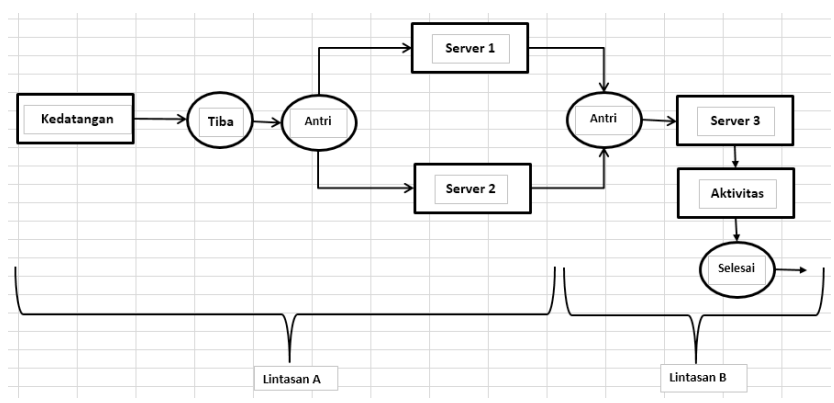

Gambar 3. Sistem Serial

Pada bagan terlihat lintasan entiti dapat dibagi menjadi dua bagian, yaitu lintasan A dan lintasan B. Hal ini dilakukan semata-mata agar memudahkan dalam membuat programnya. Script untuk lintasan pun kita buat menjadi dua sebagai berikut:

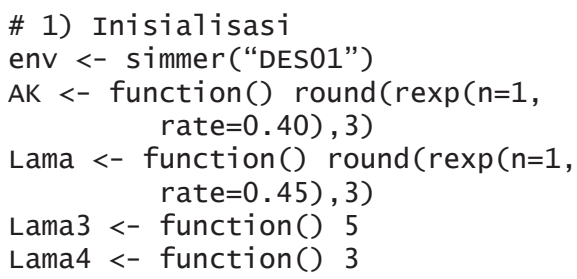


\# 2) Pendefinisian lintasan

1intas_B <- trajectory() \%>\%

seize("server3") \%>\%

timeout (Lama3) \%>\%

release ("server3") \%>\%

timeout(Lama4) \# aktivitas tanpa

\# resource (tidak ada antrian)

Tintas_A <- trajectory() \%>\%

seize("server") \%>\%

timeout (Lama) \%>\%

release("server") \%>\%

join(1intas_B)

\section{\# 3) Penambahan resources dan pem- \\ \# bangkitan kedatangan entiti env $\%>\%$ \\ add_resource("server", 2) \%>\% \\ add_resource("server3", 1) \%>\% \\ add_generator("entiti", \\ lintas_A, AK) \%>\% \\ $\operatorname{run}(100)$}

\# 4) Mengambil hasil simulasi

output.arr <- get_mon_arrivals(env)

output.resc <- get_mon_resources(env)

Perhatikan komponen ke-2 pada program. Pendefinisian lintasan dengan menggunakan fungsi trajectory() dipecah dua menjadi Lintasan_A (Lintas_A) dan Lintasan_B (Lintas_B). Lintasan_B diletakkan pada bagian atas, sebelum Lintasan_A, karena fungsi trajectory dengan objek Lintasan_A, di dalamnya ada memanggil Lintasan_B. Jadi trajectory Lintasan_B harus dikenal lebih dahulu sebelum trajectory Lintasan A dibaca. Hal ini terjadi karena program dibaca dari atas ke bawah. Aktivitas tanpa sumberdaya ada pada lintasan B, yang dilambangkan pada diagram dengan bentuk segiempat dengan nama "Aktivitas" yang tidak didahului oleh lingkaran oval antrian. Pada script diwakili oleh fungsi timeout (Lama4).

\subsection{Sistem dengan lebih dari satu jenis entiti}

Misalkan setelah dipelajari lebih lanjut, ternyata ada dua jenis entiti yang masuk kedalam sistem yang diberi nama entitiA dan entitiB. Diasumsikan entitiA datang setiap 8 menit sekali, sedangkan entitiB datang setiap setiap 12 menit sekali. Dibatasi ada 100 entitiA dan 50 entitiB yang harus menyelesaikan lintasan. Lama waktu yang dibutuhkan untuk memproses entitiA (pada server 1 atau 2) adalah menyebar Eksponensial dengan rate 1/7 per unit waktu, sedangkan entitiB (pada server 1 atau 2) membutuhkan waktu yang juga menyebar eksponensial tetapi dengan rate 1/12 per unit waktu (nilai asumsi ini diberikan semata-mata, agar program dapat dijalankan). Untuk menyederhanakan model, diasumsikan bahwa entitiA datang secara konstan setiap 8 unit waktu sekali, sedangkan entiti B datang setiap 12 unit waktu sekali. Bagan lintasannya akan digambarkan seperi berikut ini:

Pada bagan diperlihatkan, bahwa ada dua lintasan baru, yaitu kedatangan entitiA dan entitiB. Pada program R objek lintasan ini diberi nama lintas entA dan lintas entB. Pada kedua lintasan ini, setiap entiti yang tiba akan diberi nilai atribut dengan nama "Lama", yang akan digunakan untuk menentukan lamanya layanan baik diserver 1 atau di server 2. Kompleksitas program, digambarkan oleh bagan lintasan berikut:

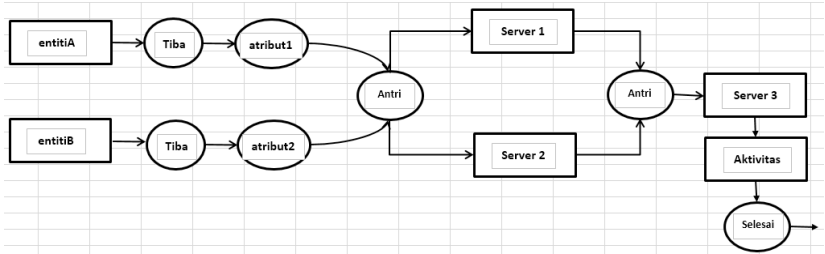

Gambar 4. Sistem dengan lebih dari satu jenis entiti

Script R diberikan sebagai berikut:

\# 1) Inisialisasi

env <- simmer("DES01")

AK <- function() round $(\operatorname{rexp}(n=1, \operatorname{rate}=0.40), 3)$

Lama3 <- function() 5

Lama4 <- function() 3

\# 2) Pendefinisian Tintasan

lintas_B <- trajectory() \%>\%

seize("server3") \%>\%

timeout (Lama3) \%>\%

release ("server3") \%>\%

timeout (Lama4)

1intas_A <- trajectory() \%>\%

seize("server") \%>\%

timeout (Lama) \%>\%

release ("server") \%>\%

join(1intas_B)

1intas_entA <- trajectory() \%>\% set_attribute("1ama",

function() $\operatorname{rexp}(1,1 / 7)) \%>\%$ join(1intas_A)

1intas_entB <- trajectory() \%>\% set_attribute("1ama",

function() $\operatorname{rexp}(1,1 / 12)) \%>\%$

join(1intas_A)

\# 3) Penambahan resources dan

\# pembangkitan kedatangan entiti

env \%> \# env adalah nama objek

\# 1ingkungan yang telah \# didefinsikan diawa 1

add_resource("server", 2) \%>\%

add_resource("server3", 1) \%>\%

add_generator("ent_A",

lintas_entA, at (cumsum(rep ( 8 , 100))), mon=2) \%>\%

add_generator("ent_B",

lintas_entB, at (cumsum(rep $(12$, 50))), mon=2) \%>\%

run() $\%>$ invisible()

\# 4) Mengambil hasil simulasi

output.arr <-

get_mon_arrivals(env)

output.resc <-

get_mon_resources(env)

output.attr $<-$

get_mon_attributes(env)

Pada komponen inisialisasi, tidak lagi ada pemberian nilai untuk objek 1 ama, karena nilai ini ditentukan oleh nilai atribute setiap entiti yang didefinikan pada trajectory 1intas_entA dan 1intas_entB. Fungsi yang digunakan adalah set_attribute. Sedangkan pada komponen ke-3 (penambahan resources dan pembangkitan kedatangan) argumen mon pada fungsi add_generator, 
diberi nilai 2, sehingga dapat dimonitor oleh fungsi get_ mon_attributes, yang akan memberikan tabel untuk nilainilai atribut setiap entiti.

\subsection{Replikasi}

Proses kompleksitas model akan berlanjut terus, sehingga benar-benar mencerminkan sistem yang akan ditiru. Kompleksitas tersebut dapat berupa percabangan (Branching), Lopps, Batching dan Reneging. Penggunaan komponen-komponen itu tentu tergantung, apakah sistem memerlukan itu. Akan tetapi, setiap simulasi akan membutuhkan proses replikasi, yaitu pengulanngan simulasi sampai R kali $(\mathrm{R}>100)$. Proses replikasi ini bertujuan untuk memperoleh simpangan baku dari pendugaan-pendugaan parameter sistem.

Berikut ini adalah script $\mathrm{R}$ untuk proses replikasi model, menggunakan fungsi lapply yang tersedia pada paket base. Script $\mathrm{R}$ berikut ini untuk melakukan pengulangan sebanyak 100 kali

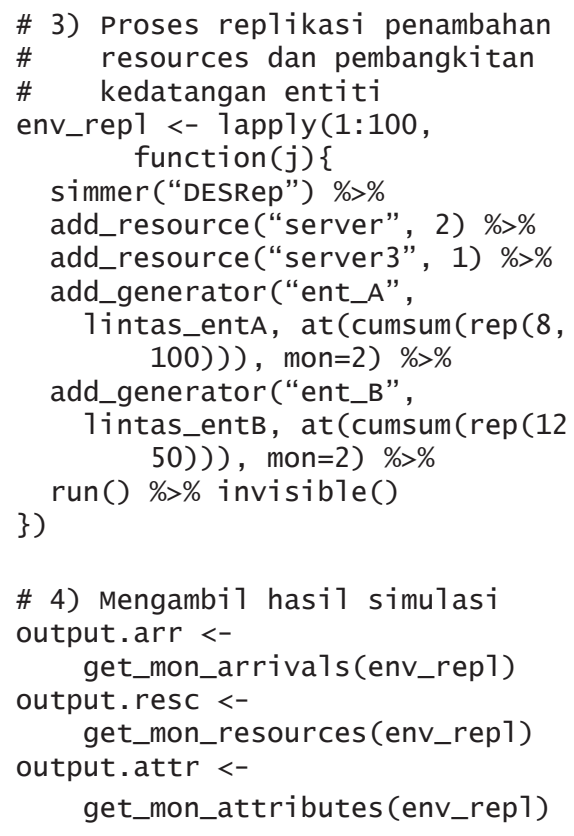

\subsection{Analisis Output dengan "dplyr"}

Paket "dplyr" sangat membantu dalam memanipulasi data dalam bentuk data frame, seperti membuat ringkasan data, mengolah kolom-kolom dan membentuk kolom baru dan seba-gainya. Pada proses replikasi simulasi diper-oleh hasil berupa data frame, yaitu output. arr, output. resc, dan output.attr. Script berikut akan mentransformasi output menjadi berkelas tbl, yaitu kelas data yang digunakan oleh paket dplyr.

out.arr <- as_tibble(output.arr)

out.resc <- as_tibble(output.resc)

out.arr <- as_tibble(output.attr)

sapply(list(out.arr, out.resc, out.attr), class)

$$
\begin{aligned}
& \text { \# output } \\
& \begin{array}{cll}
{[, 1]} & {[, 2]} & {[, 3]} \\
{[1,] \text { "tb1_df" }} & \text { "tb1_df" } & \text { "tb1_df" } \\
{[2,] \text { "tbl” }} & \text { "tb1" } & \text { "tb]" }
\end{array} \\
& {[3,] \text { "data.frame" "data.frame" "data.frame" }}
\end{aligned}
$$

Sekarang ketiga objek (out . arr, out . resc, dan out. attr) telah ditransformasi menjadi berkelas tb1, disamping juga berkelas data. frame, dan siap untuk dioleh dengan paket dplyr. Dimensi ketiga objek set data ter-sebut adalah:

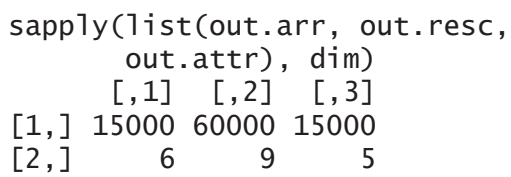

Jadi out.arr memiliki 15.000 baris dan 6 kolom, out.resc dengan 60.000 baris dan 9 kolom, sedangkan out. attr memiliki 15.000 baris dan 5 kolom.

\subsection{Peringkasan Hasil Simulasi}

Peringkasan berikut menghasilkan antrian terpanjang pada setiap server (resource), yaitu

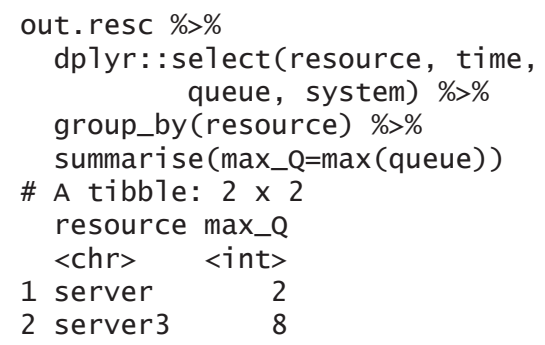

Antian terpanjang terjadi pada server3 yaitu sampai 8 entiti. Script berikut ini memberikan rata-rata panjang antrian untuk setiap resorce per replikasi, yaitu

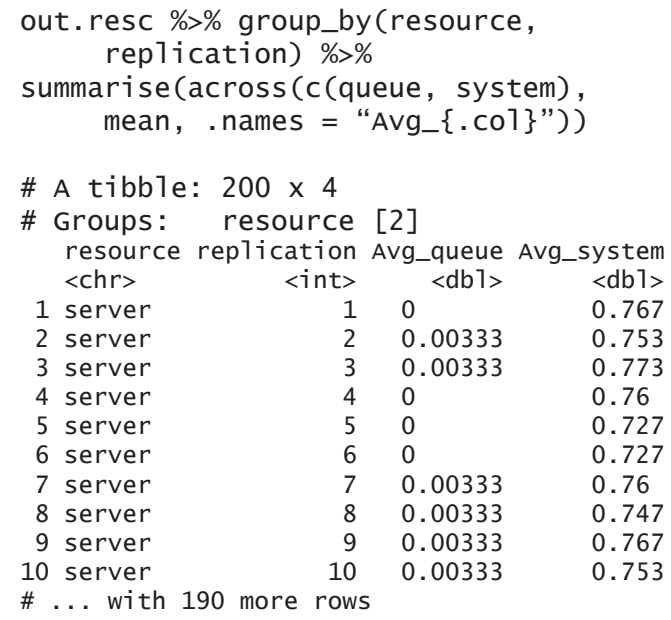

Bila ingin mendapatkan lamanya entity ada dalam antrian dan ada di dalam sistem, maka dapat digunakan perintah mutate pada $d p l y r$, yaitu sebagai berikut,

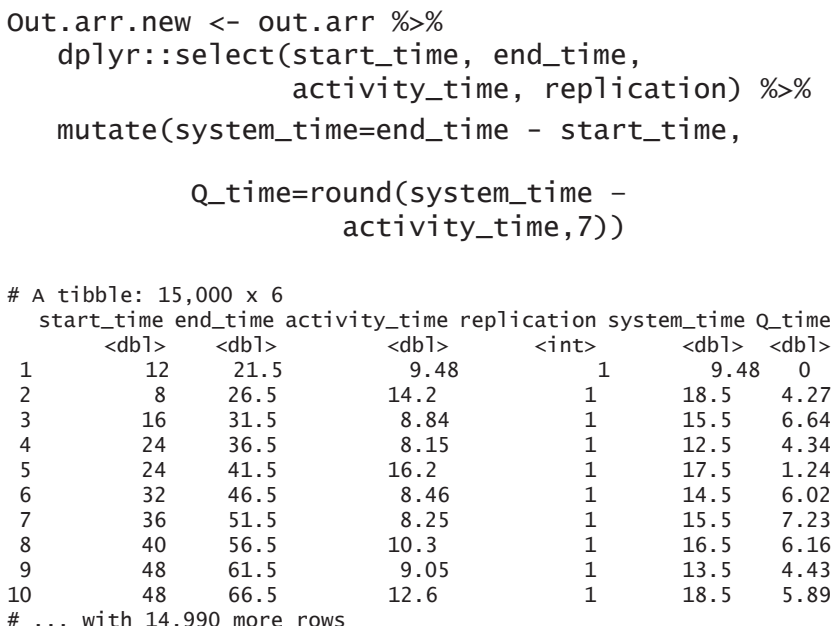


Fungsi mutate menghasilkan kolom baru yaitu system_time yang memberikan lamanya entity di dalam system dan Q_time yang mem-berikan lamanya entity di dalam antrian, kemudian hasil ini disimpan pada objek data out.arr. new. Berdasarkan ouput terakhir ini, dapat dicari nilai rata-rata lamanya entiti di dalam system dan lamanya entiti di dalam antrian, yaitu sebagai berikut:

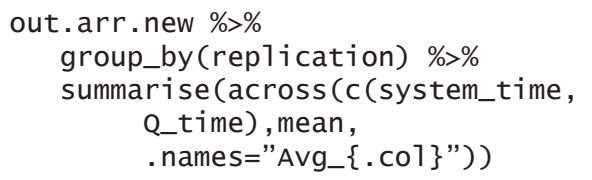

\# A tibble: $100 \times 3$

replication Avg_system_time Avg_Q_time

$\begin{array}{rrrr} & <\text { int } & <\text { db } 7> & <\text { db7> } \\ 1 & 1 & 25.0 & 14.8 \\ 2 & 2 & 23.6 & 13.4 \\ 3 & 3 & 23.8 & 13.4 \\ 4 & 4 & 22.9 & 12.5 \\ 5 & 5 & 21.5 & 11.5 \\ 6 & 6 & 24.3 & 14.1 \\ 7 & 7 & 23.8 & 13.5 \\ 8 & 8 & 23.2 & 13.2 \\ 9 & 9 & 26.2 & 15.9 \\ 10 & 10 & 26.4 & 16.2\end{array}$

Jika yang diinginkan adalah rata-rata untuk keseluruhan replikasi, maka perintah di atas dapat dilanjukan menjadi sebagai berikut:

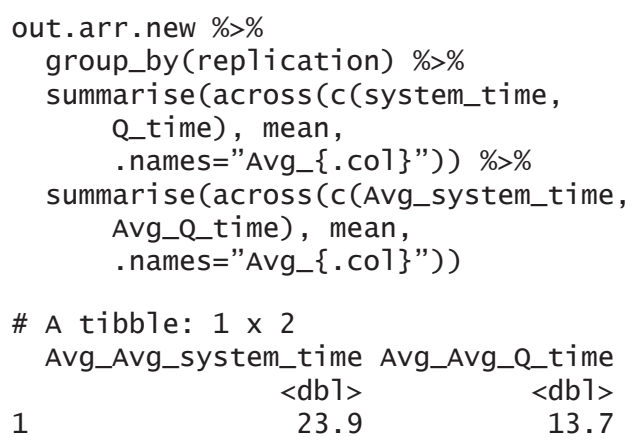

\subsection{Pendugaan Interval Kepercayaan}

Berdasarkan objek data out.arr.new diper-oleh rata-rata lamanya entiti di dalam sistem dan di dalam antrian, yang diberikan oleh kolom Avg_system_time dan Avg_Q_time. Kedua kolom tersebut dapat diambil dengan menggunakan fungsi attach.

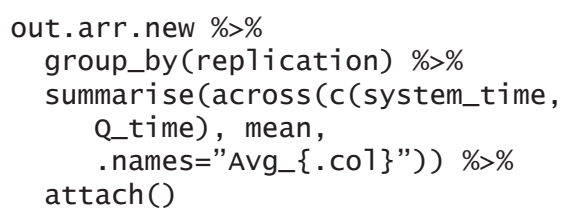

head(Avg_system_time,4)

[1] $25.02309 \quad 23.61274 \quad 23.81376 \quad 22.86765$

head (Avg_Q_time, 4)

[1] $14.76864 \quad 13.41091 \quad 13.3551212 .51495$

Galat baku (standard error) untuk lamanya entiti di dalam sistem dan di antrian, dapat didekati oleh simpangan baku dari rata-rata per replikasi, diperoleh sebagai berikut:

(SE_system <- sd(Avg_system_time))

[1] 1.64213
(SE_Q <- sd(Avg_Q_time))

[1] 1.620795

Sehingga margin error untuk kedua variable adalah 2 kali galat bakunya. Jadi penduga interval kepercayaan masing-masing untuk lamanya entiti di dalam sistem dan lamanya entiti di dalam antrian adalah sebagai berikut:

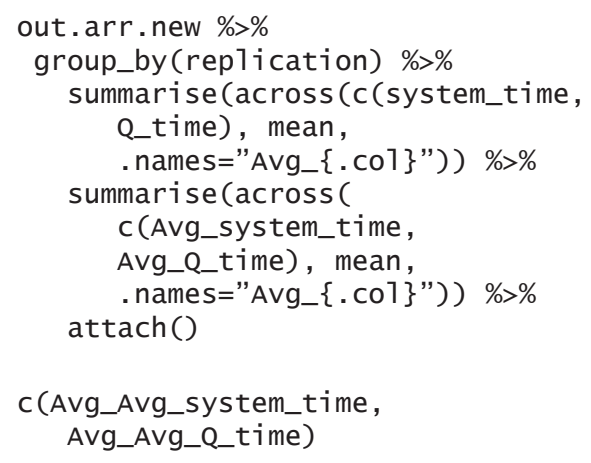

[1] 23.9067113 .66237

Jadi pada kasus ini, interval kepercayaan rata-rata lamanya entiti di dalam sistem adalah:

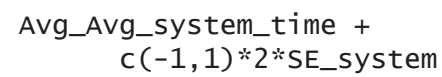

[1] $20.62245 \quad 27.19097$

Sedangkan interval kepercayaan rata-rata lamanya entiti di dalam antrian adalah:

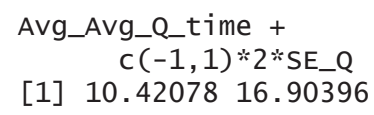

\section{KESIMPULAN}

R API pada simmer terdiri dari dua elemen utama, yaitu lingkungan simulasi simmer - yang diciptakan melalui fungsi simmer()-, dan objek lintasan (dibuat oleh fungsi trajectory()). Seperti yang telah dipaparkan dalam tulisan ini simulasi dengan simmer, berarti membangun lingkungan simulasi, dengan satu atau lebih lintasan-lintasan. Lingkungan simulasi akan menyimpan dan memonitor semua nilai dan perubahan-perubahan yang terjadi pada peubah acak dan atribut entiti selama simulasi berlangsung. Pengembangan simulasi terhadap sistem akan lebih mudah dilakukan, dengan membuat suatu bagan alir (flowchart) yang merepresentasikan sistem dengan jelas. Semua nilai-nilai peubah acak dan perubahan-perubahan yang terjadi terhadapnya, dapat diambil kembali dari lingkungan simulasi simmer, dengan menggunakan perintah get_mon_. Hasil dari perintah get_mon_ ini berupa objek dengan kelas data. frame, yang selanjutnya dapat diolah kembali dengan menggunakan fungsi-fungsi R lainnya terutama dplyr.

Agar hasil simulasi menjadi lebih menarik, akan lebih baik dikembangkan kembali pemba-hasan tentang simmer. plot dan dihubungkan dengan kemampuan package ggplot2, yang sangat baik dalam memvisualisaikan suatu dataset. Kemampuan simmer dalam memba-ngun simulasi sirkular (seperti sistem tranportasi pulang pergi untuk 
angkutan umum massal), juga belum diekplorasi lebih jauh. Kompleksitas sistem belum sepenuhnya dieksplorasi pada tulisan ini seperti adanya layanan prioritas untuk entiti tertentu, balking dan reneging, serta entiti berbentuk bulk.

\section{DAFTAR PUSTAKA}

Banks, Jerry, John Carson II, Barry Nelson, and David Nicol. Discrete-Event System Simulation, 5th Edition. (2014) Pearson Education Limited, Edinburgh Gate, England

Lander, Jared P. (2017). R for Everyone: Advanced Analytics and Graphics 2nd Edition. Pearson Education, Inc. USA.

Smeets, Bart and Inaki Ucar. (2020). Intro-duction to simmer. https://r-simmer.org/articles/simmer-01-introduction.html

Ucar, Inaki, Bart Smeets, \& Arturo Azcorra. (2019). simmer: Discrete-Event Si-mulation for R. Journal of Statistical Software, Vol 90, Issue 2. https:// www.jstatsoft.org/article/view/v090i02 